\title{
Impact of HIV/AIDS on mortality and nutritional recovery among hospitalized severely malnourished children before starting antiretroviral treatment
}

\author{
Léon G. Blaise Savadogo ${ }^{1,2,3}$, Philippe Donnen ${ }^{3}$, Fla Kouéta ${ }^{4}$, Eléonore Kafando ${ }^{4}$, Philippe Hennart ${ }^{3}$, \\ Michèle Dramaix ${ }^{3}$ \\ ${ }^{1}$ Department of Epidemiology and Public Health, Child and Mother Health, Nutrition and Survival Unit, Institut Supérieur des Sci- \\ ences de la Santé (IN.S.SA), Bobo Dioulasso University, Bobo-Dioulasso, Burkina Faso \\ ${ }^{2}$ Nutritional Rehabilitation Unit, Ouagadougou, Burkina Faso \\ ${ }^{3}$ CR2-Epidemiology-Biostatistics-Clinical Research, School of Public Health, Université Libre de Bruxelles (ULB), Brussels, Belgium \\ ${ }^{4}$ Ouagadougou Pediatric Hospital and University of Ouagadougou, Ouagadougou, Burkina Faso \\ Email: gueswende@hotmail.com
}

Received 5 October 2013; revised 1 November 2013; accepted 9 November 2013

Copyright (C) 2013 Léon G. Blaise Savadogo et al. This is an open access article distributed under the Creative Commons Attribution License, which permits unrestricted use, distribution, and reproduction in any medium, provided the original work is properly cited.

\begin{abstract}
In low income countries, severe acute malnutrition remains a major problem for $\mathrm{HIV}$-infected children and an important risk factor for mortality. This study aims to analyze HIV impact on mortality rate and nutritional recovery among severely malnourished HIV/AIDS uninfected and infected children. This was a retrospective cohort study conducted from data of 521 hospitalized severely malnourished children. We used Pearson's Chi square test to compare proportions; and Student's independent t-test to compare means; general linear model to analyze repeated measurements. We used mortality relative risk with confidence interval (CI 95\%), Kaplan-Meir survival curves and Cox proportional hazard models to analyze the HIV impact on mortality rate. Case fatality rate differed significantly from SAM HIV uninfected $(10.7 \%)$ and HIV infected children $(39.7 \%)$, p $<0.001$. Mortality relative risk was $3.71,95 \%$ IC [2.51 - 5.47] for HIV infected children. Kaplan-Meir survival curves differed significantly between the two groups, (p Log Rank < 0.001). Cox regression adjusted mortality relative risk of HIV infected children was 4.27 , CI: $2.55-7.15, \mathrm{p}<0.001$. Mean weight gain differed significantly among infected children, $p<$ 0.001. Anthropometric Z-scores means evolution differed significantly between HIV infected and uninfected children and within each group's subjects for WHZ $(p<0.001)$ and WAZ $(p<0.001)$. Mortality relative risk was 3.71 times higher for HIV infected children. Multiples infections and metabolic compli-
\end{abstract}

cations have synergism on death occurrence in sever acute malnutrition; when associated to HIV infection, case fatality rate increases many times. Weight gain and anthropometrics index evolution were very slow for SAM HIV infected children, and specific diet may be needed for more nutritional recovery. Effective interventions, updated and adapting to local country context, to improve survival of severely malnourished HIV/AIDS infected children in HIV and SAM prevalent settings are urgently needed in the area of SAM's community-based treatment approach.

Keywords: Mortality; Severely Malnourished; HIV/AIDS; Children

\section{INTRODUCTION}

In low income countries, severe acute malnutrition (SAM) remains a major killer of children under five years of age. To cover large numbers of children with severe acute malnutrition, treatment approach combines, today, community-based approach with ready-to-use therapeutic foods or other nutrient-dense foods, at home, without being admitted to a health facility or a therapeutic feeding centre, and inpatient treatment with a facilitybased approach for those malnourished children with medical complications [1]. In low income countries, despite efforts, numbers of infants continue to be born with HIV, as less than $35 \%$ of pregnant women received HIV testing and less than $48 \%$ pregnant women are receiving effective treatment for preventing mother-tochild transmission. Severe acute malnutrition (SAM) 
remains a major problem for HIV-infected children and an important risk factor for mortality [2-8].

Observational studies reported high HIV prevalence among malnourished children [9-12]. A systematic review and meta-analysis of children presented with SAM in sub-Saharan Africa reported an HIV seroprevalence of $29 \%$ with data from 17 studies [13]. If severely malnourished uninfected children can be successfully treated in community based approach, those who are HIV/AIDS infected, seriously ill, need facility based treatment. Challenges, for facilities and feeding therapeutic centers, are case management for HIV/AIDS infected SAM children. This study aims to measure case fatality rate and nutritional recovery during nutritional rehabilitation, among severely malnourished HIV/AIDS uninfected and infected children before starting antiretroviral treatment, and to show urgent need for specific intervention needed for integrating HIV management in the area of SAM's community-based treatment approach.

\section{MATERIAL AND METHODS}

\subsection{Study Design and Site}

This was a retrospective cohort study conducted from data of severely malnourished children hospitalized, between 2006-2009, at a feeding therapeutic center, based on inpatient treatment approach, in Ouagadougou. At this center, trained care providers staff, leaded by a medical doctor, was in charge of the treatment. Case management and follow-up care were based on WHO guidelines for inpatient treatment of severely malnourished children.

\subsection{Study Population}

During the considered period, severe acute malnutrition (SAM) diagnostic is based on severe wasting, as a weight-for-height below $-3 \mathrm{SD}$ or below $70 \%$ of median (based on NCHS reference) or the presence of nutritional oedema affecting both feet.

For HIV testing, the child blood sample were collected and identified by a single code and immediately transferred to Ouagadougou pediatric hospital laboratory for analyses. To reduce testing cost, a first level antibody tests was used and polymerase chain reaction (PCR) test was used when antibody test was positive.

\subsection{Standard of Care}

Patients received standard inpatient treatment for severely malnourished children with initial stabilization phase and rehabilitation phase. Treatment procedures were similar for marasmus and kwashiorkor. For feeding, daily and hourly volume was adapted to the child weight and presence of oedema.

HIV/AIDS infected children was referred to pediatric hospital to be integrated to HIV/AIDS follow up cohort and eligible's patients received antiretroviral treatment.

All nutritional treatment, antiretroviral treatment and opportunistic infections management were offered, using national guidelines. Testing including PCR and transport to pediatric hospital were offered.

\subsection{Study Samples Size}

Data of 521 severely malnourished children, tested for HIV have been considered for analysis.

\subsection{Data Collection}

Trained research nurses collected data on children's socio-demographic (sex, age, parent residence), feeding, anthropometry and clinical signs at admission. Anthropometry was daily measured. The child age was determined using date of birth recorded from its mother pregnancy card and date of admission. Weight was measured in $\mathrm{kg}$ using recommended scale with a precision of $0.1 \mathrm{~kg}(100 \mathrm{~g})$. Length of less than 2 years old child was measured in centimeters using length board (horizontal infantometer) with a precision $0.1 \mathrm{~cm}(1 \mathrm{~mm})$ and height of 2 years or older child able to stand was measured in cm using height board (vertical stadiometer) with a precision $0.1 \mathrm{~cm}(1 \mathrm{~mm})$. If the child was not able to stand for any reason, length was measured using length board and subtract $0.7 \mathrm{~cm}$ to convert in to height.

Oedema of both feet was automatically considered as severely malnourished case.

Mid-upper arm circumference (MUAC) (cm) was recorded for completed 3 months children.

After discharge, a monthly visit was organized for children.

\subsection{Laboratory Analyses}

Anti body test and PCR for HIV diagnosis were performed for all children at Ouagadougou pediatric hospital laboratory.

\subsection{Study Outcomes}

The study aimed to analyze the impact of HIV/AIDS mortality rate and nutritional recovery, during nutritional rehabilitation among severely malnourished HIV-infected and uninfected children, before starting antiretroviral treatment.

\subsection{Statistical Analyses}

Usual statistics methods were applied. We used Pearson's Chi square test or Fisher's exact test to compare proportions; and Student's independent t-test to compare means. General linear model has been used to analyze repeated measurements. Mortality relatives risks with 
confidence interval (CI 95\%) have been calculated to estimate the impact of HIV on mortality rate. KaplanMeir survival curves and Cox proportional hazard models has been used to investigate the impact of HIV infection on mortality rate.

The following lower and upper standard deviation (SD) boundaries have been used: WHZ $(-4,+6)$, HAZ $(-6,+6)$ and WAZ $(-6,+6)$. Weight gain was calculated as $\mathrm{g} / \mathrm{kg} /$ day. 20 .

The data were analyzed using SPSS software version

\section{RESULTS}

During the considered period, SAM community-based treatment approach with ready-to-use therapeutic foods was not common. Children were addressed from rural facilities to feeding therapeutics centers. We tested HIV status of 521 admitted severely malnourished children, $73(14.0 \%)$ was HIV/AIDS infected (not prevalence, as testing was not systematic for all SAM children).

The proportion of HIV/AIDS infected children did not differ between sex categories ( $\%$ male HIV infected $=$ 14.30 , and $\%$ of female HIV infected $=13.60, \mathrm{p}=0.81$ ) and between age categories ( $\% 0-11$ mo HIV infected $=$ 13.80; \% 12 - 23 mo HIV infected = 13.30; \% 24 - 35 mo HIV infected $=18.10, \%>35$ mo HIV infected $=6.70, \mathrm{p}$ $=0.40)$.

At admission, WHZ, WAZ and MUAC means differed significantly between HIV/AIDS infected and uninfected SAM children (Table 1).

Case fatality rate differed significantly from SAM HIV uninfected (10.7\%) and HIV infected children (39.7\%), $\mathrm{p}<0.001$. Mortality relative risk was 3.71, 95\% IC [2.51 - 5.47] for HIV infected children. Kaplan Meir

Table 1. HIV infected and uninfected children anthropometry at admission to the therapeutic feeding center.

\begin{tabular}{cccc}
\hline & HIV & HIV+ & p \\
\cline { 2 - 3 } & $\mathbf{n}$ & $\mathbf{n}$ & \\
\hline WHZ admission & 421 & 71 & \\
Mean (SD) & $-3.41(0.81)$ & $-3.68(0.70)$ & 0.008 \\
WAZ admission & 388 & & \\
Mean (SD) & $-4.17(0.79)$ & $-4.50(0.80)$ & 0.002 \\
HAZ admission & 414 & & \\
Mean (SD) & $-2.75(1.27)$ & $-2.97(1.21)$ & 0.18 \\
& & & \\
MUAC admission & 342 & 70 & \\
Mean (SD) & $10.13(1.30)$ & $9.59(1.21)$ & 0.001 \\
& & & \\
\hline
\end{tabular}

survival curves differed significantly between the two groups, (p Log Rank < 0.001) (Figure 1).

From Cox regression, variables for adjustment were: HIV status, age categories, admission WHZ categories, admission WAZ categories and admission MUAC categories. Variables entered step by step using backward stepwise ( $p$ for entry $=0.05$ ); variables in the equation at step 3 were: HIV status, admission WHZ categories and admission MUAC categories.

Adjusted mortality relative risk of HIV infected children was 4.27, CI: 2.55 - 7.15, Wald Chi square p-value $<0.001$ ) (Tables 2(a) and (b)).

At discharge, mean weight gain $(\mathrm{g} / \mathrm{kg} / \mathrm{d})$ differed significantly between infected children (weight gain $=4.64$ (2.82)) and uninfected children (weight gain $=9.04$ (5.04)), $\mathrm{p}<0.001$.

From admission to discharge, anthropometric Z-scores means evolution differed significantly between HIV infected and uninfected children and within each group's subjects: WHZ (between group: $\mathrm{p}<0.001$; within subject: $\mathrm{p}<0.001$ ), WAZ (between group: $\mathrm{p}<0.001$; within subject: $\mathrm{p}<0.001$ ) (Figures 2 (a) and (b)).

\section{DISCUSSION}

The study aimed to analyze the impact of HIV/AIDS mortality rate and nutritional recovery during nutritional rehabilitation among severely malnourished HIV-infected and uninfected children, before starting antiretroviral treatment.

From the 521 severely malnourished children tested, $14.0 \%$ was HIV/AIDS infected and their mother HIV status was unknown. According to 2010 UNAIDS statistics, in low and middle-income countries, 35\% of pregnant women received HIV testing and 48\% received ART for preventing mother-to-child transmission. HIV infection undermines nutritional status by metabolic changes. In this study, intra hospital mortality rate was

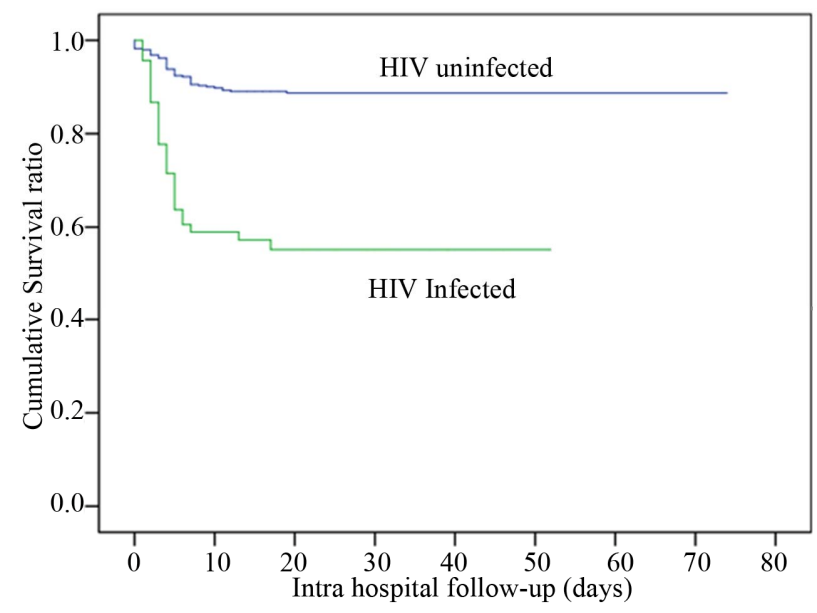

Figure 1. Kaplan-Meier survival curves. 
Table 2. (a) Univariate mortality analysis and Cox proportional hazard model; (b) Cox proportional hazard model.

(a)

\begin{tabular}{|c|c|c|c|c|}
\hline & \multicolumn{4}{|c|}{ Univariate analysis } \\
\hline & n & $\begin{array}{l}\text { Mortality } \\
\text { rate }\end{array}$ & $\begin{array}{c}\text { HR } \\
\text { (IC 95\%) }\end{array}$ & $\mathbf{p}$ \\
\hline \multicolumn{5}{|l|}{ Age (mo) } \\
\hline $0-11$ & 138 & 16.70 & $2.50[0.62-10.04]$ & \multirow{4}{*}{0.53} \\
\hline $12-23$ & 248 & 15.30 & $2.30[0.58-9.05]$ & \\
\hline $24-35$ & 105 & 13.30 & $2.00[0.48-8.32]$ & \\
\hline$>35$ & 30 & 6.70 & 1.00 & \\
\hline \multicolumn{5}{|l|}{ HIV } \\
\hline Infected & 73 & 39.70 & $3.71[2.51-5.47]$ & \multirow{2}{*}{$<0.001$} \\
\hline Uninfected & 448 & 10.70 & 1.00 & \\
\hline \multicolumn{5}{|l|}{ WHZ adm } \\
\hline$\leq-4$ & 121 & 24.80 & $2.54[1.39-4.63]$ & \multirow{3}{*}{0.003} \\
\hline$[-4--3]$ & 238 & 13.90 & $1.42[0.77-2.60]$ & \\
\hline$[-3--2]$ & 133 & 9.80 & 1.00 & \\
\hline \multicolumn{5}{|l|}{ WAZ adm } \\
\hline$\leq-4$ & 269 & 19.3. & $2.61[0.67-10.12]$ & \multirow{3}{*}{0.009} \\
\hline$[-4--3]$ & 155 & 9.00 & $1.22[0.29-5.07]$ & \\
\hline$[-3--2]$ & 27 & 7.40 & 1.00 & \\
\hline \multicolumn{5}{|l|}{ HAZ adm } \\
\hline$\leq-4$ & 97 & 14.40 & $0.94[0.54-1.65]$ & \multirow{3}{*}{0.97} \\
\hline$[-4--3]$ & 124 & 15.3 & $1.00[0.60-1.65]$ & \\
\hline$[-3--2]$ & 261 & 15.3 & 1.00 & \\
\hline \multicolumn{5}{|l|}{$\begin{array}{c}\text { MUAC } \\
\text { admission }\end{array}$} \\
\hline$\leq 110 \mathrm{~mm}$ & 263 & 19.8 & $2.09[1.31-3.34]$ & \multirow{2}{*}{0.001} \\
\hline$>110 \mathrm{~mm}$ & 233 & 9.4 & 1.00 & \\
\hline
\end{tabular}

(b)

\begin{tabular}{ccc}
\hline & RR Adjusted \\
\hline & RR (IC 95\%) & p \\
\hline HIV Status & & \\
Infected & $4.27[2.55-7.15]$ & $<0.001$ \\
Uninfected & 1.00 & \\
WHZ admission & & \\
$\leq-4$ & $1.93[0.94-3.94]$ & 0.08 \\
{$[-4--3]$} & $1.10[0.56-2.15]$ & \\
{$[-3--2]$} & 1.00 & \\
MUAC admission & & 0.05 \\
$\leq 110 \mathrm{~mm}$ & $1.70[0.99-2.93]$ & \\
$>110 \mathrm{~mm}$ & 1.00 & \\
\hline
\end{tabular}

approximately four times higher in severely malnourished HIV-infected children (39.7\%) than in non-infected children $(10.7 \%)$; and mortality relative risk was 3.71 times higher for HIV infected children. Authors reported excess mortality risk associated to HIV infection among malnourished children [14-16].

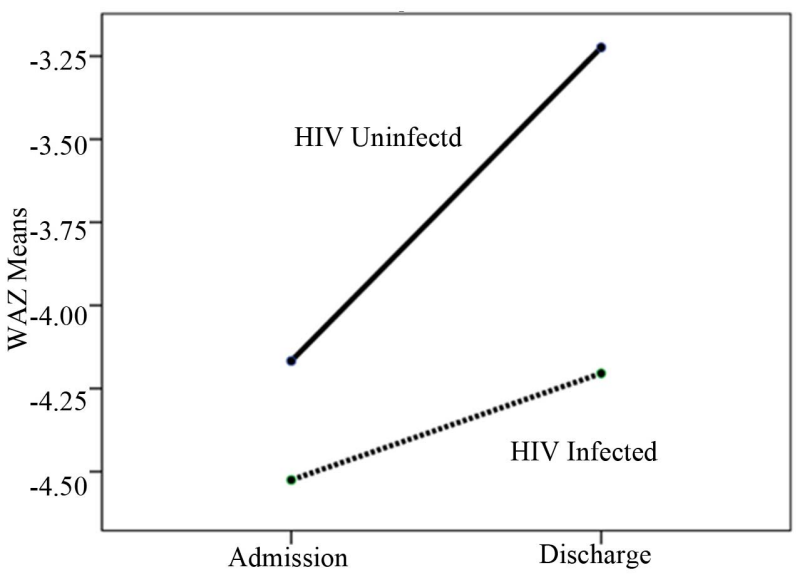

(a)

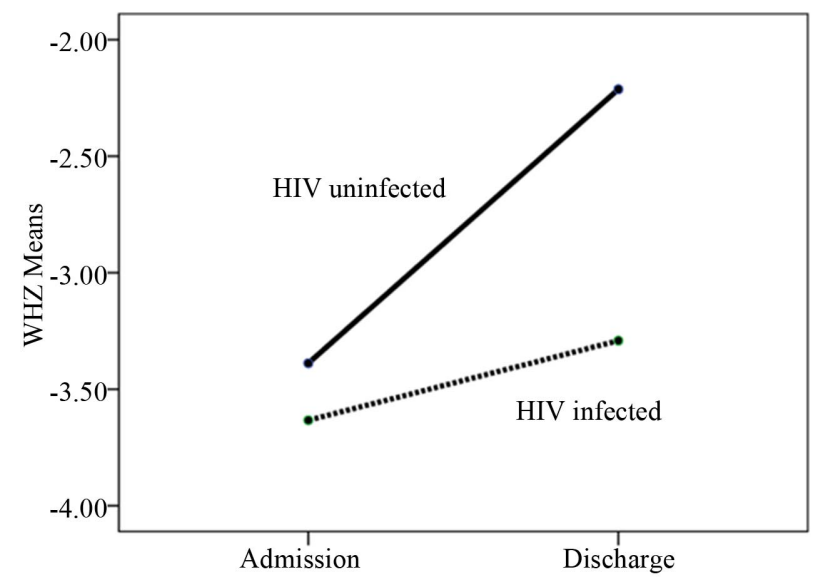

(b)

Figure 2. (a) and (b) From admission to discharge anthropometric Z-scores means evolution within each group subjects and between groups.

Many of the metabolic responses are described in severe malnutrition, but the responses in HIV-infected severely malnourished children are unknown [17]. Both severely malnourished uninfected and HIV infected children present co-morbidity [14] but may have deferent treatment, due to complex pathophysiological, metabolic, and pharmacological interactions.

Multiples infections and metabolic complications have synergism on death occurrence in sever acute malnutrition [18]. When associated to HIV infection, case fatality rate increases many times [19]. The challenge is great in the first week of the intra hospital treatment of SAM HIV infected children, as death occurred largely during this period. HIV infected children metabolic changes and nutrients can lead to death and needs must be considered in therapeutic and care guidelines.

In our study, at discharge, mean weight gain $(\mathrm{g} / \mathrm{kg} / \mathrm{d})$ anthropometric Z-scores means evolution, differed significantly between HIV infected and uninfected severely children. Weight gain and anthropometric index evolu- 
tion were very slow for SAM HIV infected children. In SAM HIV infected children, anorexia remaining common and specific diet is may be needed for more nutritional recovery. Young HIV-infected severely malnourished children, perinatally infected with HIV may have poor response to management as set out in current guidelines.

Antiretroviral therapy (ART) becomes increasingly available globally in the world, not in all the low incomes countries. The impact of highly active antiretroviral therapy on HIV infected children survival becomes evident [20]. In the context of delay to ART initiation for children admitted in feeding therapeutic centers or in rural facilities. Evidence of ART role on improving nutritional status is clearer. Due to delay (diagnosis, procedures, socio-cultural context), initiation to ART for SAM HIV infected cannot be before several weeks. There is no evidence on efficacy and impact on mortality rate to start ART immediately or after stabilization phase or rehabilitation phase. Optimum timing of ART initiation remains a challenge [21].

\section{CONCLUSION}

Effective interventions, updated and adapting to local country context to improve survival of severely malnourished HIV/AIDS infected children in HIV and SAM prevalent settings are urgently needed.

\section{ACKNOWLEDGEMENTS}

Commission Universitaire pour le Développement (CUD), Belgium, laboratory analysis, medicines for opportunistic diseases.

\section{REFERENCES}

[1] World Health Organization, World Food Programme, United Nations System Standing Committee on Nutrition and United Nations children's Fund (2007) Communitybased management of severe acute malnutrition. A Joint Statement by the World Health Organization, the World Food Programme, the United Nations System Standing Committee on Nutrition and the United Nations Children's Fund.

http://www.who.int/nutrition/publications/severemalnutrit ion/978-92-806-4147-9 eng.pdf

[2] Kimani-Murage, E.W., Norris, S.A., Pettifor, J.M., Tollman, S.M., Klipstein-Grobusch, K., Gómez-Olivé, X.F., Dunger, D.B. and Kahn, K. (2011) Nutritional status and HIV in rural South African children. BMC Pediatrics, 11, 23. http://dx.doi.org/10.1186/1471-2431-11-23

[3] Puoane, T., Sanders, D., Chopra, M., Ashworth, A., Strasser, S., McCoy, D., Zulu, B., Matinise, N. and Mdingazwe, N. (2001) Evaluating the clinical management of severely malnourished children-A study of two rural district hospitals. South African Medical Journal, 91, 137-141.

[4] Deen, J.L., Funk, M., Guevara, V.C., Saloojee, H., Doe, J.Y., Palmer, A. and Weber, M.W. (2003) Implementa- tion of WHO guidelines on management of severe malnutrition in hospitals in Africa. Bulletin of the World Health Organization, 81, 237-243.

[5] Kessler, L., Daley, H., Malenga, G. and Graham, S. (2000) The impact of the human immunodeficience virus 1 on the management of severe malnutrition in Malawi. Annals of Tropical Paediatrics, 20, 50-56. http://dx.doi.org/10.1080/02724930092075

[6] Chintu, C., Luo, C., Bhat, G., DuPont, H.L., MwansaSalamu, P., Kabika, M. and Zumla, A. (1995) Impact of the human immunodeficiency virus type 1 on common pediatric illnesses in Zambia. Journal of Tropical Pediatrics, 41, 348-353.

http://dx.doi.org/10.1093/tropej/41.6.348

[7] Ndekha, M.J., Manary, M.J., Ashorn, P. and Briend, A. (2005) Home-based therapy with ready-to-use therapeutic food is of benefit to malnourished HIV-infected Malawian children. Acta Paediatrica, 94, 222-225. http://dx.doi.org/10.1111/j.1651-2227.2005.tb01895.x

[8] Padmapriyadarsini, C., Pooranagangadevi, N., Chandrasekaran, K., Subramanyan, S., Thiruvalluvan, C., Bhavani, P.K. and Swaminathan, S. (2009) Prevalence of underweight, stunting, and wasting among children infected with human immunodeficiency virus in South India. International Journal of Pediatrics, Article ID: 837627

[9] Madec, Y., Germanaud, D., Moya-Alvarez, V., Alkassoum, W., Issa, A., Amadou, M., Tchiombiano, S., Pizzocolo, C., Huber, F., Diallo, S. and Abdoulaye-Mamadou, R. (2011) HIV prevalence and impact on renutrition in children hospitalised for severe malnutrition in Niger: An argument for more systematic screening. PLoS One, 6, e22787.

http://www.ncbi.nlm.nih.gov/pmc/articles/PMC3145755/ pdf/pone.0022787.pdf http://dx.doi.org/10.1371/journal.pone.0022787

[10] Ticklay, I.M., Nathoo, K.J., Siziya, S. and Brady, J.P. (1997) HIV infection in malnourished children in Harare, Zimbabwe. East African Medical Journal, 74, 217-220.

[11] Prazuck, T., Tall, F., Nacro, B., Rochereau, A., Traore, A., Sanou, T., Malkin, J.E., Apaire-Marchais, V., Masson, D. and Dublanchet, A. (1993) HIV infection and severe malnutrition: A clinical and epidemiological study in Burkina Faso. AID, 7, 103-108. http://dx.doi.org/10.1097/00002030-199301000-00016

[12] Mgone, C.S., Mhalu, F.S., Shao, J.F., Britton, S., Sandström, A., Bredberg-Råden, U. and Biberfeld, G. (1991) Prevalence of HIV1 infection and symptomatology of AIDS in severely malnourished children in Dars Es Salaam, Tanzania. Journal of Acquired Immune Deficiency Syndromes, 4, 910-913. http://dx.doi.org/10.1097/00126334-199109000-00013

[13] Fergusson, P. and Tomkins, A. (2009) HIV prevalence and mortality among children undergoing treatment for severe acute malnutrition in sub-Saharan Africa: A systematic review and meta-analysis. Transactions of the Royal Society of Tropical Medicine and Hygiene, 103, 541-548. http://dx.doi.org/10.1016/j.trstmh.2008.10.029

[14] Heikens, G.T., Bunn, J., Amadi, B., Manary, M., Chhagan, 
M., Berkley, J.A., Rollins, N., Kelly, P., Adamczick, C., Maitland, K., Tomkins, A. and Blantyre Working Group (2008) Case management of HIV-infected severely malnourished children: Challenges in the area of highest prevalence. Lancet, 371, 1305-1307. http://dx.doi.org/10.1016/S0140-6736(08)60565-6

[15] Bunn, J. and Kerac, M. (2007) Excess mortality risk associated with HIV in a large Malawi nutritional rehabilitation unit. Malawi Medical Journal, 19, 95.

[16] Chinkumbha, J., Tomkins, A.M., Banda, T., Mkangama, K. and Fergusson, P. (2008) The impact of HIV on mortality during inpatient rehabilitation of severely malnourished children in Malawi. Transactions of the Royal Society of Tropical Medicine and Hygiene, 102, 639-644. http://dx.doi.org/10.1016/j.trstmh.2008.04.028

[17] Heikens, G.T. (2007) How can we improve the care for severely malnourished children in Africa? PLOS Medicine, 4, e45.

http://www.ncbi.nlm.nih.gov/pmc/articles/PMC1783670/ pdf/pmed.0040045.pdf http://dx.doi.org/10.1371/journal.pmed.0040045

[18] Maitland, K., Berkley, J.A., Shebbe, M., Peshu, N., English, M. and Newton, C.R. (2006) Children with severe malnutrition: Can those at highest risk of death be identified with the WHO protocol. PLOS Medicine, 3, e500. http://www.ncbi.nlm.nih.gov/pmc/articles/PMC1716191/ pdf/pmed.0030500.pdf http://dx.doi.org/10.1371/journal.pmed.0030500

[19] Abirekere-Iriso, E., Musoke, P. and Kekitiinwa, A. (2006) Bacteraemia in severely malnourished children in an HIV-endemic setting. Annals of Tropical Paediatrics: International Child Health, 26, 319-328. http://dx.doi.org/10.1179/146532806X152845

[20] Cardoso, C.A., Pinto, J.A., Candiani, T.M., Carvalho, I.R., Linhares, R.M. and Goulart, E.M. (2012) The impact of highly active antiretroviral therapy on the survival of vertically HIV-infected children and adolescents in Belo horizonte, Brazil. Memórias do Instituto Oswaldo Cruz, 107, 532-538. http://dx.doi.org/10.1590/S0074-02762012000400014

[21] Prendergast, A., Bwakura-Dangarembizi, M.F., Cook, A.D., Bakeera-Kitaka, S., Natukunda, E., Nahirya Ntege, P., Nathoo, K.J., Karungi, C., Lutaakome, J., Kekitiinwa, A. and Gibb, D.M. (2011) Hospitalization for severe malnutrition among HIV-infected children starting antiretroviral therapy. AIDS, 25, 951-956. http://dx.doi.org/10.1097/QAD.0b013e328345e56b 